\title{
Palavra impossível, a condição poética de Ruy Belo
}

Wagner Moreira Centro Federal de Educação Tecnológica de Minas Gerais

\author{
(...) e escrever poemas cheios de honestidades \\ várias e pequenas digitações gramaticais \\ com piscadelas de olho ao "real quotidiano", \\ aqui o autor diz: desculpe, sr. dr., mas: \\ merda!, 1971 - e agora,
}

Herberto Helder

$\sqrt{\begin{array}{l}\text { anuel Gusmão, ao abrir o seu artigo "Algumas } \\ \text { variações em resposta à poesia de Ruy Belo", } \\ \text { dentre outras coisas, afirma sobre essa poesia que }\end{array}}$ "a multiforme pujança do seu compromisso com a linguagem, a sua dimensão de intensa e insistente dedicatória, aquilo que [...] parece como o crescimento da densidade da sua habitação do tempo" ${ }^{\prime 1}$ são marcas recorrentes dela. Tais palavras vão ao encontro da proposta deste ensaio que se propõe a investigar o paradigma que responda ao procedimento poético de Belo, dando ênfase à noção de experiência dedicada à realidade em somatória com a composição da escrita trabalhada de modo artístico.

Implicadas às questões da linguagem, da inscrição afetuosa de lembrança ou do tempo, ainda Gusmão evidencia

${ }^{1}$ GUSMÃO, 2012, p. 409 
o traço irônico como aquele que apresenta a distância entre o quem do discurso e o quem da "frase local", frase cotidiana. Essa face corrosiva da poesia de Belo faz surgir uma possibilidade de recepção para o título do livro Boca bilingue, pois este aponta para um exercício poético que "junta a consciência e o fazer da poesia enquanto artifício ou artefato e o operar dela como fala humana, mesmo que produzida na solidão e na distância."2

Ida Ferreira Alves, em comunicação intitulada "Ruy Belo: boca bilingue" ${ }^{\prime}$, ensina que a expressão "boca bilingue" provém do Livro da sabedoria, atribuído a Salomão, mais especificamente da sentença "A sabedoria detesta a boca bilingue". Dessa maneira, Alves aponta para a tradição religiosa evocada pelo nome do livro, associando-a ao que o próprio Belo declara: "bilingue é toda a poesia". Dois fatores devem ser destacados dessa sentença bíblica, o primeiro diz respeito ao fato dela se referir à abertura de possibilidades do uso da língua, seja ela praticada no sentido de um saber de origem divino; seja pelo hábito vulgar de uma comunicação entre os humanos; ou mesmo posto sob a égide da criatividade da criança em seu exercício exploratório da linguagem - isso se se considerar certa recepção do texto bíblico. O segundo evidencia a vivência religiosa do autor como ex membro da ordem Opus Dei e, parece, por meio dessa, chega-se ao contato com uma tradução, diga-se, mais ortodoxa, do Livro da sabedoria. Explica-se melhor essa questão ao se informar que atualmente as versões que circulam com maior intensidade não trazem mais a sentença que dá origem ao nome do livro do poeta, optando os tradutores do texto bíblico por outra formulação linguística.

Assim, o bilinguismo tende para uma errância no uso da língua, o que apresenta um acentuado grau de afastamento entre o discurso poético e o discurso religioso, sendo o último apenas

${ }^{2}$ GUSMÃO, 2012, p. 413

${ }^{3}$ ALVES, 2008, p.215 
mais uma categoria da qual se pode lançar mão para o exercício criativo da palavra humana. Espelhando esse movimento criativo da manifestação verbal escrita, verifica-se o que se poderia chamar de transformação do sujeito histórico em um sujeito poético, isto é, o autor, ao se desligar da ordem religiosa e enfatizar em seu trabalho poético essa outra possibilidade de se experimentar o existir, afirma a condição poética como um ritual, no mínimo, tão importante quanto o que se deixou de praticar. O poético aparece como "um compromisso ético com o mundo e uma experiência estética fundamental" ${ }^{4}$, tanto que a poesia se estabelece, se faz presença por meio da densidade e da intensidade verbais. Por outra via, poderia se pensar, nesse sentido, que
"no ethos da sua poesia, haja sempre uma unidade concreta (ou seja, habitada por uma contradição que se desequilibra num ou noutro sentido) entre a experiência de uma "terrível solidão" e um princípio de religação que deixa ler [...]; uma unidade entre a solidão repetidamente afirmada e algo que é da ordem da compaixão, enquanto paixão com, da ordem da defesa da agredida humanidade dos humanos. ${ }^{5}$

Essas palavras de Gusmão se referem ao livro Aquele grande rio Eufrates (2004). Todavia, descrevem com precisão cirúrgica a condição poética que atravessa o livro posterior que ora se analisa. Essas linhas de força que se anunciam e perpassam a obra de Belo - a solidão e o princípio de religação - fazem pensar em um ato de revalorização do passado que revigora o valor da experiência do sujeito seja em seu aspecto biográfico, seja em sua recepção dos textos com os quais estabelece um diálogo. No mínimo, deve-se levar em consideração duas

\footnotetext{
${ }^{4}$ ALVES, 2008, p. 215

${ }^{5}$ GUSMÃO, 2012, p. 414
} 
tradições textuais: a religiosa e a poética, ambas agindo por meio do ato criativo e instaurando o discurso poético beliano. Isso sem se esquecer da presença acentuada da vivência cotidiana que funciona como ponto de inflexão dessa escrita.

O primeiro poema do livro, "Ce funeste langage", reafirma todo o campo semântico insinuado pelo título do livro. O título é uma citação de Jean de Racine, da tragédia Andromaque, de 1667, considerada a primeira grande obra daquele autor. Ela trata dos desencontros amorosos entre quatro personagens principais: Andrômaca [viúva de Heitor e prisoneira de Pirro], Hermione [filha de Helena e prometida a Pirro], Pirro (Neoptolemus) [filho de Aquiles e rei de Épiro] e Orestes [filho de Agamenon]. Essa ação, que gera tensão e tem como desenlace a morte, empresta seus traços mais intensos ao poema. $\mathrm{O}$ verso da peça que serve de ponto de inflexão para o texto de Belo é " Quittez, Seigneur, quittez ce funeste langage", em livre tradução: "deixe, Senhor, deixe a linguagem fatal".

Belo, como se pode ver, opera um corte no verso original. Ele retira, exatamente, o primeiro sexto de sílabas poéticas da frase dodecassilábica - Quittez, Seigneur, quittez - que tem por condução de sentido certa negação do ato que se anunciará na segunda parte do verso, a saber, a linguagem mortal. Note-se que não é a morte que se quer anunciar, como no texto de Racine, mas o sistema pelo qual se constitui o ato de comunicar algo. Não se quer enfatizar o ato de morrer, mas aquilo que o diz o meio que se faz outra coisa que não aquela referenciada: a linguagem funesta. Em outras palavras, pode-se inferir dessa circunstância que a poesia de Belo se interessa pela linguagem poética, tendo como forças tangenciais as coisas, os fatos, os conceitos e as ideias, todos se colocando a serviço da ação criativa da palavra.

Esta palavra é qualificada como sinistra, danosa, agonizante, lutuosa, arruinadora e inevitável. Uma palavra 
que tem o poder de dar origem a, de fundar algo com a força do trânsito entre duas condições: a do existir e a do desaparecimento. Em seu primeiro quarteto - o poema é um soneto petrarquiano, de versos dodecassílabos - pode-se verificar uma alusão à figura bíblica de Lázaro, quando se abre o texto ordenando-se que a "palavra", qualificada como duvidosa, indecisa, perplexa, vacilante em seu modo de ser, apresenta um grau elevado de dificuldade para ganhar vida. Nessa circunstância na qual se encontra essa espécie de nascimento da palavra, há também a sugestão de uma diminuição da potência divina que ganha contorno humanizado ao ser identificada com um ser capaz de esquecer, de ter como falha a sua memória, portanto. Ainda como uma espécie de descrição do ambiente no qual se cria a palavra, tem-se a verificação do ato de iluminar, todavia, este se efetiva de maneira indireta, por meio de certo encobrimento que parece poder envolver e camuflar o que toca, insinuando-se um padecimento, uma amargura que tende para a tristeza. É nessa atmosfera que nasce a palavra, sob a ordem do poeta: "Levanta-te e caminha".

A segunda estrofe apresenta o canto como uma promessa que vislumbra um horizonte incerto, não nomeado, mas que se anuncia apenas para aquele sujeito capaz de exercer o ato criativo verbal, mesmo este ignorando o que a condição da morte traz para o existir da palavra. O poeta, esse sujeito criador como um deus humanizado em sua condição histórica, portanto, transitória, tem, ao desempenhar o seu papel, o poder do religare. Esse enlaçamento entre um espaço humano, espaço de vida, e outro sobre-humano, espaço de morte, faz pensar na verticalização poética como um procedimento possível nos textos de Belo. Sua poesia anuncia, por meio deste texto, uma potência, mesmo que inconsciente, e uma propensão para voltar-se para o que motiva os viventes, como se fosse um ânimo, um espírito pensante que traz a palavra com viço intenso. 
O tempo é a matéria que dimensiona a terceira estrofe. É ele que dá a ver o passado como um exercício longínquo, distante do momento presente, pelo menos enquanto uma sensação. Também como uma espécie de cisma, de ruminação que tende para o pensamento atento e minucioso que tanto pode derivar para uma insistência, uma certeza, quanto pode se dirigir para uma suposição. Esse tempo é modificado pela figura criada por Leon Tolstói: Ana Karenina. Parece aqui que, por um lado, o aspecto humano da força amorosa retorna à pauta e, por outro, o da vida cotidiana, se se pensar no romance do escritor russo. Digo melhor: o romance traz em seu enredo certa discussão sobre o viver no meio rural como pano de fundo da aventura afetuosa da protagonista que dá nome ao livro. A alteração promovida na percepção temporal diz respeito ao fato de se introduzir o caráter ficcional como categoria criativa, seja para exemplificar as variações do afeto humano, seja para reforçar a condição material da existência em sociedade. A memória, nesse caso, aparece como a força maior do excerto do poema, quer pelo que será imaginado sobre o passado, quer pela lembrança da estratégia de escrita do romance, o monólogo de caráter psicológico, envolto na figura de Karenina. A forma pessoal que deriva dessa realização da lembrança traz à tona a questão da solidão que perpassa o texto poético, bem como a da intimidade que o determina, singularizando a sua expressão.

O soneto clássico beliano se fecha com a nomeação dessa linguagem poética como sendo a "palavra impossível". A interjeição que abre a última estrofe dá o ar de surpresa, de espanto, ou mesmo de desejo para essa unidade linguística. Isto se deve ao fato dela fazer aparecer outra palavra, muito distante dela, afirmando a diferença existente entre ambas. A outra palavra é caracterizada como "útil" e "portátil", e dela se pode inferir, portanto, que seja facilmente transportável e proveitosa, no sentido de trazer vantagem por servir para a realização de 
algo ou de alguma coisa. Já a "impossível" causa um franquearse do texto poético, isto é, dá-lhe certa espontaneidade e independência na manifestação do desimpedimento em relação a tudo que pode vir a ser expressado. Percebe-se esta como a "lábil criança", ou seja, a palavra impossível é aquela que, movente por natureza, experimenta livremente com as possibilidades da linguagem que se constitui como um olhar aparentemente inocente, arrojado, fascinado e instigado pelo que se dá a ver.

"Ce funeste langage" cumpre um papel programático ao se colocar em função de epígrafe se se pensar na relação existente entre os blocos de poemas do livro Boca bilingue. Seja por sua posição gráfica na obra, ou por sua temática metalinguística que enfatiza a palavra como canto inaugural que conduz aquele que a vivencia para o espaço de viço vigoroso. Isto somado ao exercício solitário da memória - construção singular de um mundo próprio em diálogo com o mundo da realidade -, revela a diferença dessa linguagem poética que se quer autônoma e primitiva. Esse entendimento apresentado sobre a forma livre mínima do enunciado poético deriva para todas as cinco subpartes do texto beliano que se concatenam com títulos e epígrafes próprias: "Vita Beata" - Si amitti uita beata potest, beata esse non potest. Cic., Fin., 2,27,86; "Sete Coisas Verdadeiras" - Esto nom he apocrifo mas cousa muy verdadeira. I Crónica Breve de Santa Cruz. PMH - Scriptores, v. I; "Tempo Duvidoso" ...Diogo Lopes Pacheco, quem em tempo tão duvidoso se veio de Castela com seus filhos João Fernandes, Lopo Fernandes e Fernão Lopes, por se lançarem com o mestre. Crónica de D. João I, c. CLXI; "O testamento de Elvira Sanches"; e "Solidão e Morte" - E assi ficou Vallěça ssoo... /... e erã muy coitados acerca da morte. Crónica Geral de Espanha, c. DCVII 6-7 e 9-10.

"Vita Beata", ou em tradução livre, vida venturosa, o conjunto de hábitos que levam à felicidade, traz como motivação dessa parte uma frase de Cícero, de Finibus que pode ser 
compreendida como uma possibilidade de perda da existência bem-aventurada, o que leva à condição de infelicidade. Dessa maneira, o título ganha um sentido irônico por conter em si uma dupla potência de recepção, podendo ser compreendido como um paradoxo que traz o afeto da alegria e da tristeza simultaneamente. Essa aparente contradição parece ser a força dessa seção. Assim se deve observar a série "Portugal SacroProfano", em especial, "A charneca e a praia" - subtítulo que empresta a ambiguidade ao sujeito poético e à sua linguagem. O poema se inicia narrando um dia natalino, isto é, aquele que deve ser o momento de alegria pelo fato de se reconhecer nele a possibilidade de renovação da vida. Sua segunda estrofe abre com uma partícula adversativa e, fazendo uma referência direta à epígrafe de autoria de Cícero, traz para o sujeito poético o peso da reflexão que o consome, anunciando uma tristeza duradoura, e esta supostamente pode funcionar como um empecilho para a condição da alegria. O sujeito se descobre angustiado com essa dúvida. Solitário, parece descrer dos momentos do verão, ou de um passado que pode se identificar com o presente ao revelar o ser que olha e que é olhado nesse exercício de memória; a terceira estrofe parece apontar para o isolamento do poeta quando este se reconhece perdido entre as linhas temporais do passado, do presente e do futuro. Isto aponta para um estado abissal que faz girar a consciência a partir do olhar dado pelos versos.

É por meio do diálogo com a "anima naturaliter christiana" que se apresenta o esquecimento como uma ação capaz de permitir a construção da memória para um eu que se faz em sua própria vivência. $\mathrm{O}$ ato de escrever traz o vivido e a existência futura, tudo como uma mudança contínua em uma espécie de delírio. O processo de subjetivação encontra uma exterioridade na qual o sujeito se conhece vertiginosamente a cada instante e se institui como escritor. A alternativa é viver a sobriedade 
do mundo factual, cronológico, físico, mundo que necessita da salvação divina - universo regulamentado pela presença humana. Finaliza-se o poema afirmando a sua ação de fazer e de esquecer, de ter um nome, aparentar a alegria e ser percebido. Esse aparecimento do sujeito como aquele que realiza os desejos para além das normas e que recebe um reconhecimento por ser o que é corrobora a condição humana do poeta e de sua fusão de afetos.

Em "Sete coisas verdadeiras", a máxima faz alusão ao diálogo entre o que é inautêntico e o que é genuíno. Retirada de manuscritos quatrocentistas do Mosteiro de Santa Cruz de Coimbra, esse conjunto de textos heterogêneos apresenta quatro crônicas historiográficas que tiveram como primeiro editor Alexandre Herculano nos Portugaliae Monumenta Historica PMH. Mais uma vez, a epígrafe empresta ao título um alto grau de incerteza, dirigindo este último para uma recepção antagônica entre o que é dito e o que pode ser percebido. Também faz pensar em uma construção histórica que se baseia no movimento da clandestinidade, movimento fora do cânone, estabelecendo, dessa maneira, um acentuado grau de subjetividade para o que recebe o valor positivo nesta versão do conjunto do conhecimento humano.

Ainda se pode dizer que este segmento se constitui por sete poemas, que se veem reificados sob a égide desse olhar histórico subjetivado. Essa marca de concreção pode muito bem ser observada no poema "Glauco e Diomedes". Estas personagens da Ilíada, por preservarem a relação com seus antepassados como forma de obterem uma recompensa futura, operam um pacto de hospitalidade e trocam as armaduras entre si: Glauco sede a de ouro e Diomedes a de bronze. Com este ato, juram não se enfrentar em batalha. $O$ poema de quatro estrofes apresenta como palavra inicial nas três primeiras o termo "Assim". Este pode designar um modo particular; uma 
natureza semelhante; uma quantidade ou um tamanho imenso; ou mesmo um movimento de aproximação. Este último parece reunir os demais sentidos em si e, por conseguinte, no poema, apresentar o laço entre as personagens da Ilíada trazendo para o texto beliano a temática do reconhecimento. Segundo Duarte "o ato de reconhecer implica antes na verificação da existência de um vínculo entre os que o experimentam, mas que lhes era ignorado." ${ }^{6} \mathrm{E}$ em sua primeira estrofe, o poema parece apresentar exatamente o vínculo de philía - amizade que se baseia na hospitalidade remontada aos avós - indicado pela relação dos heróis ilíacos. A duração temporal rege o nascimento e a morte dos elementos naturais e dos homens, para o primeiro fenômeno, as coisas se deslindam, decompondo-se em seus elementos constituintes; para o segundo fenômeno, os seres são isentos de penalidades, encontram o perdão.

A segunda estrofe dirige a condição de falência das coisas e seres não divinos da primeira para o espaço indeterminado da origem, lugar primitivo que apresenta o sujeito em sua inquietude. Este desassossego que impede a tranquilidade, como os elementos naturais, dissolve-se em seus próprios componentes. Aqui se verifica uma correspondência entre o natural e o humano que aparentam originar-se de uma mesma condição, espécie de philía mais remota. Por outro modo, o humano também é um elemento natural e reconhecê-lo faz parte da dissolução de si em meio às coisas.

Os elementos que tendem para uma grandeza infinita como a "noite" e o "mar" são postos na terceira estrofe tal qual aqueles descritos anteriormente no poema, a saber, o "sol", a "lua", o "homem", a "terra mãe", o "dia", o "mar", a "praia do início". Pode-se inferir que todos eles tendem a apresentar por meio de si essa prodigalidade incomensurável. Deriva dessa

${ }^{6}$ DUARTE, 2007, p. 48 
circunstância a noção de filho e de mãe dada pelos versos: ao mesmo tempo que se pode verificar uma identidade imediata entre ambos, também se pode perceber a produção de uma diferença na figura materna que passa a se reconhecer como o outro de si mesmo, a partir da experiência de se dar a origem a um ser, o filho. Parece haver no poema, uma percepção maquínica dessa vivência original, uma vez que a estrofe termina associando esse evento ao que serve de orientação e, simultaneamente, à engrenagem que permite a continuidade de um movimento. Esse exercício não aparente e desconhecido torna-se concreto no existir de um sujeito a partir dos versos de Belo. Isto é corroborado pelo dístico final do texto que anuncia a inevitabilidade da morte para os seres e, ao mesmo tempo, a garantia da vida, em termos de espécie: "E por maior cadáver que na carne leve / a ave retransmite à ave tudo quanto vive".

Vale lembrar que a figura da ave é central na lírica portuguesa como metáfora do poeta e do canto. Aqui o canto ilíaco encontra sua releitura no canto beliano; Glauco e Diomedes destacam-se como a cena do reconhecimento atualizada para o sujeito poético; e a tradição se move por agregação de uma cena de amizade que faz dialogar o passado com o presente.

A terceira seção, "Tempo Duvidoso", apresenta em sua abertura um excerto da Crónica de D. João I que nomeia o clã dos Pacheco. Influentes em Portugal e em Castela, essa família esteve presente em momentos decisivos da constituição da nação portuguesa, como em 1355, ano da morte de Inês de Castro, ou em 1384, quando o pai, Diogo Lopes Pacheco, junto aos seus filhos, João Fernandes Pacheco, Lopo Fernandes e Fernão Lopes Pacheco apoiariam o Mestre de Avis contra os castelhanos. Pode-se verificar que o título da seção é um recorte da compilação dos fatos históricos e junto a esta dirige-se para um espaço de incerteza dos valores e ações humanas, bem como enfatiza um exercício político como forma de sobrevivência. 
"Versos do pobre católico" é um poema que evidencia a falta de clareza sobre a qualidade humana e sua moral. $\mathrm{O}$ sujeito que se apresenta se diz em falta com a "Senhora da Assunção", pois ele "Nem palavras nem coisas [tem] para o teu altar". Diferenciando-se da multidão de crentes, só lhe resta a própria "enorme incorrigível distracção" como oferta ao ser sobre-humano. A amargura é o sentimento predominante nessa relação entre o sujeito e a fé, uma vez que ele ignora o como "nadar / no mar de piedade em que outros se comprazem". Disso se pode inferir um estado pessimista em relação à fé, o que aponta um valor hesitante ou mesmo de suspeição que prevalece no poeta. Chama a atenção o fato de esse sujeito se apresentar como um descrente e ainda se ver impelido a comparecer, junto com a multidão de fiéis, ao alcance do olhar da figura sagrada - este momento parece ser aquele da dúvida anunciada no título da seção.

Por outra via, em "Ácidos e óxidos", vê-se o sujeito apresentar seu desejo de agir instintivamente e negar as necessidades sociopolíticas, como em "Não, cargos ou honras não". Em seu "país perdido" o tempo passa e se vive a reboque da sensação do momento, neste caso, "o verão", estação que desloca e relativiza a importância dos eventos oficiais de reconhecimento do sujeito como "Curriculum atestado testemunho opinião". Estação que evidencia o "nome" como o que reduz o ser, revelando o seu inferno, o seu lugar de tormento, no qual a falta e a efemeridade aparecem como a marca que rege o sujeito.

O sujeito é uma questão de tempo. Neste caso, tempo duvidoso que se vivencia de maneira burocrática e/ou a gozar os momentos de prazer iluminado. Tempo angustiado entre o circunstancial e o que encerra o ser em si ou mesmo em sua morte. Um sofrimento devido a consciência da passagem da vida e relativo ao apagamento que se segue ao se morrer, como diz o poeta: "Ou porventura deixas algum rasto?" 
Em ambos os poemas verifica-se uma política do sujeito, voltada para as questões pessoais e em desacordo com as temáticas coletivas. Há uma preocupação em se colocar no mundo que é dado - com suas regras e formas, seja sob os aspectos naturais, seja sob os políticos - de um modo singular e intransferível. Isto significa retirar de si uma linhagem e se reconhecer como indivíduo falível. O peso da tradição se resolve e se encerra no eu e este, em vários momentos, se julga indeciso em seus valores e atos sociopolíticos. Todavia, neste caso, sabe-se que ele escreve e a sua escrita é "certo tipo de [...] declaração" - um índice do que se refletiu sobre a existência criativa - a poesia.

A penúltima seção, "O Testamento de Elvira Sanches", faz menção a um dos textos considerados primeiros da língua portuguesa. Segundo Costa,

O testamento feito por Elvira Sanches ao mosteiro de Vairão em 1193 está também redigido em português e tem merecido dos filólogos e historiadores da Literatura Portuguesa quase tanta aceitação como o Auto de partilhas de 1192, em que interveio ela e mais três irmãos? .

Todavia, a datação da escrita em português é alvo de estudos e discussões acadêmicas até os dias atuais, como se pode ver a seguir:

O Doutor Rui de Azevedo não encontrou na escrita deste documento provas suficientes contra a sua autenticidade, ao contrário do que aconteceu com o Auto de partilhas: «M. Rui de Azevedo ne trouve pas, en examinant son écriture, les mêmes motifs que dans la charte de 1192 pour douter de son authenticité. Il en a cependant relevé quelques caractères

${ }^{7}$ COSTA, 1979. p. 09 
qui ne sont pas fréquents dans l'écriture de la fin du XIIeme siècle».

Embora o traçado geral da escrita deste testamento não tenha uma feição tão tardia como a do Auto de partilhas, encontram-se, todavia, nele características paleográficas muito semelhantes às deste e que não são próprias dos fins do séc. XII.

[...]

Tendo Elvira Sanches vivido nos fins do séc. XII e princípios do XIII, não se pode pôr a hipótese de o seu testamento ser um original de 1293 ou época próxima.

Deve tratar-se, por conseguinte, como no Auto de partilhas, da tradução de um original de 1193 feita nos fins do séc. XIII, tradução essa que será porventura a responsável pelos motivos de suspeição.

(COSTA, Revista Portuguesa de História, XVII. Coimbra, 1979. p. 10)

Para além da evidência histórica, há a busca de uma expressão original, que se apresenta com traços do elemento de fundação de uma língua - ao se abandonar a expressão latina e experimentar com a formalização portuguesa - isso parece também ser a marca do título. Nesse sentido, ele aponta para a questão da apropriação de uma língua sobre outra ou sobre si mesma, e suas implicações como, por exemplo, o valor da tradução como efeito de registro e como finalidade criativa, ou o estado de invenção da escrita. Também ele guarda em si a distribuição de bens como procedimento de direito e de posse do sujeito histórico.

A série "O jogador do pião" que deriva para sete poemas com o título “Variações sobre 'O jogador do pião' dispõe o primeiro poema com a forma do soneto estrambótico de dezesseis versos e os outros sendo petrarquianos. A forma excêntrica de "O jogador do pião" faz pensar na origem dessa 
forma e a sua mobilidade estrutural que variava entre os quatorze e os dezesseis versos, geralmente, distribuídos em dísticos. Nesse conjunto poético, o resgate da tradição italiana e sua modificação aponta para o ato criativo experimental ao se dirigir diretamente para o cânone universal do imaginário literário. Esse modo paradoxal permite perceber a configuração física do soneto como uma maneira de sondar as possibilidades da língua em sua versão artística; mais do que isso, a potência da construção de sentido, regida pela variação sígnica dos oito textos, corrobora o campo semântico anunciado pela epígrafe anteriormente apresentada.

Se há um bem anunciado nessa série de poemas, ele deve ser associado ao imaginário do jogo. $\mathrm{O}$ " pião", objeto móvel que deve manter-se em giro para romper com a força gravitacional, revela a maestria, o engenho do sujeito que o manipula e possui. A busca do equilíbrio por meio do movimento faz surgir a especificidade desse agrupamento poético: o jogar. Este revela outra série, agora a da qualidade artística, posta em ação - a escrita parece dar a ver algumas marcas como o entretenimento no ato de produção poética; o exercício de criação como algo necessário e prazeroso; o risco em sua face de aposta, isto é, de luta com a palavra, de convicção criativa, de confiança no bom sucesso; o movimento como oscilação incerta a disparar a potência de sentido; a destreza no trato com a técnica e com a tradição.

O "pião", objeto manipulável, por contiguidade se identifica com o sujeito que joga, o mesmo que "levanta ao céu a enxada" - portanto, uma espécie de lavrador que se deixa perceber em rodopio em sua existência angustiadamente terrena. "Quem és?" determina uma busca infrutífera do se imaginar em meio à vertigem do viver em dúvida permanente — “Voltas? rodas? regressas? rodopias?". A coisa nascida no arremesso do brinquedo cônico dirige-se 
para uma não existência, para um estado de insignificância que afasta este sujeito nato de uma condição de ser, colocando-o em falta diante de si mesmo, um "nada". Deve-se depreender disso a face de peão guardada pela homofonia e pela potência de sentido: o homem da plebe, o comum desprovido de privilégio, o eixo em torno do qual gira o mundo.

"Solidão e Morte" encerra o livro Boca bilingue. Mais uma vez a inscrição inicial nos remete para a presença histórica por meio de excerto de texto do século XIV: a Crónica Geral de Espanha, de autoria atribuída a Pedro Afonso de Barcelos, o Conde de Barcelos. Essa crônica traz a questão da reescrita com uma versão em 1344 e outra em 1400. Quanto ao conteúdo, segundo Krus,

“(...) se permanece fiel ao ideário de uma história ibérica onde conflui e se dimensiona o passado dos diversos reinos cristãos da Reconquista, incluindo o de Portugal , não deixa de manifestar uma "sistemática hostilidade" (Catalán) para com a dinastia real de Castela e uma paralela tendência para exaltar o contributo regional português na construção da história peninsular, acabando, desse modo, por atenuar a tese afonsina do primado castelhano no protagonismo hispânico." ${ }^{8}$

Por outro lado, se se pensar na questão da iluminura presente no livro, Peixeiro afirma que

Esta linguagem das imagens, incorporada na Crónica em tempo diferente do da escrita, [...] introduz um discurso novo, em que o rei se torna presente e dominante, desempenhando o papel principal. Nele assenta a legitimidade, procurando inverter, desta forma, o pendor senhorial subjacente ao texto da Crónica. [...] aqui se falou do carácter civil da imagem do

${ }^{8}$ KRUS, 1997. p. 22 
rei que também transparece nas representações da Crónica. De facto, é escassa a temática religiosa: dois funerais e um milagre, o do bispo de Santiago e o touro. Não há santos, mistérios, imagens de pendor moralizante, atitudes devocionais ou simbólica marcadamente religiosa. É a figura do rei e do seu poder, a vida, a morte, o amor, os jogos e divertimentos, a música, motivos naturais ou fantásticos, que estão presentes, acentuando a memória profana que a Crónica nos transmite. ${ }^{9}$

Se a Crônica Geral de Espanha aborda um universo complexo e variado de temas, Belo parece operar um corte em sua apropriação desse texto. Ele enfatiza a temática da solidão e da morte ao constituir uma colagem com as passagens " $E$ assi ficou Valleça ssoo... / ... e erã muy coitados acerca da morte".

O poema que encerra o livro, "Certas formas de nojo" resgata exatamente em seu título a amargura, o desgosto, o sentimento de perda de alguém, o constrangimento e a repugnância. Com numerosa e variada referência literária e histórica, o poema apresenta o afeto de desencanto de maneira sóbria, como se pode ver na passagem: "Sem incidentes sem discurso o poeta chega ali / e os detritos são o último vestígio de uma raça". A morte, "coisa extraordinária", aparece naquele que exercia o pensamento há pouco tempo, o amigo, e que deixou um rastro nas pequenas coisas cotidianas com as quais lidou, até se encontrar como cadáver: "aquele ser distante / irónico petrificado calmo diferente inacessível", mas ainda presente nesse corpo imóvel.

A memória também está posta nesse momento trágico como um desfilar de imagens de tempos passados - "Amigos praias frios luz" - e a melancolia se assevera com a incerteza sobre a própria identidade, pois o sujeito é "uma enorme

${ }^{9}$ PEIXEIRO, 2009. p. 152 
dúvida estendida da cabeça aos pés". Fica aqui a alusão, por contiguidade, de que a marca cadavérica aproxima aquele que morreu daquele que está vivo. E, dessa maneira, a solidão aparece como uma continuidade dessa condição amarga e de desnorteio do sujeito refletido pelo amigo: "Eis-te sozinho / em ti. Perdeste quanto eras no lá fora". A efemeridade do viver é o que indica que "cada um de nós apenas é também simples questão de tempo", mais uma vez o sujeito é o tempo que habita.

Deriva desse conhecimento da falência humana o modo de anunciá-la, a poesia. Esse o registro artístico que exalta a existência de forma singular, por meio de imagens prosaicas e limiares. Esse o meio de perpetuar o sentimento de perda e o desconcerto proporcionado por aquele ao sujeito.

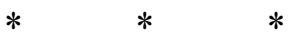

A solidão e o religare se constituem como as forças maiores em Boca bilingue. De variada maneira, Belo traz em sua poesia o estado de um sujeito amargurado pela ambiguidade das experiências existenciais. Sua perspectiva singular faz aparecer o estar só e o desejo de estabelecer ligações diversas entre o sujeito poético e os acontecimentos. Sincrônica e diacronicamente, esse sujeito busca se firmar por meio dos textos de fundação da língua portuguesa, da vivência religiosa em falta, do exercício poético em pleno viço. É este último que parece redimensionar o olhar beliano para um fazer artístico que tende para a invenção formal e imaginária de uma "palavra impossível", aquela que deixa ver a beleza estética em sua força de ato e de tensão poéticas. 


\section{Referências bibliográficas}

BELO, Ruy. Todos os poemas. Lisboa: Assírio \& Alvim, 2004. vol 1;2;3.

CICERO, Marco Túlio. Do sumo bem e do sumo mal: (de finibus bonorum et malorum). São Paulo: Martins Fontes, 2005.

COSTA, Avelino de Jesus da. Estudos de cronologia, diplomática, paleografia e histórico-linguísticos. Revista Portuguesa de História, Coimbra, XVII, 1979, p. 163.

DUARTE, Adriane da Silva. Glauco e Diomedes: uma cena de reconhecimento na Ilíada? Phaos, Campinas, vol. 7, 2007, p. 41-55.

ELIOT, T. S. A essência da poesia. RJ: São Cristovão, 1972.

FERNANDES, Fátima Regina. Os exílios da linhagem dos Pacheco e sua relação com a natureza de suas vinculações aos Castro (segunda metade do século XIV). Cuad. hist. Esp., Buenos Aires, 2014.

GUSMÃO, Manuel. Tatuagem \& Palimpsesto - da poesia em alguns poetas e poemas. Lisboa: Assírio \& Alvim, 2012.

KRUS, Luís. Crónica da conquista do Algarve. História e antologia da Literatura Portuguesa - Séculos XIII - XIV. Lisboa, Série HALP, no. 4, dezembro de 1997, p. 22.

PEIXEIRO, Horácio Augusto. Imagem e tempo - representações do poder na Crónica Geral de Espanha. Revista de História da Arte, Lisboa, n. ${ }^{\circ}$, 2009, p. 152-177.

RACINE, Jean. Andrómaca. http:/ /librodot.com. in:

http: / / losdependientes.com.ar/uploads / q338zpkonf.pdf; consultado em 15/11/2013.

TOLSTÓI, Liev. Ana Karenina. Lisboa: Europa-América, 2004. 


\section{Resumo}

O objeto desse estudo é o livro Boca Bilingue, publicado em 1966, por Ruy Belo. Ele traz em si algumas marcas que atravessam toda a obra do escritor, tais como, a postura crítica em relação ao literário e à realidade; a temporalidade; a morte; a memória. Aqui, o foco principal será a expressão solitária do eu que, em certos momentos, se deixa apreender como um ser melancólico, cujo ato criativo se dirige para a experiência do cotidiano, para a relação entre a tradição e a novidade. Como nos ensina a professora Ida Alves, em Ruy Belo "a poesia é um compromisso ético com o mundo e uma experiência estética fundamental" para a constituição do sujeito poético. A partir da análise de seus poemas, pretende-se investigar os aspectos sincrônicos e diacrônicos anunciados, com a finalidade de se estabelecer um paradigma que responda ao procedimento poético do autor, no que tange à noção de experiência dedicada à realidade e à composição poética de seu fazer criativo.

\section{Resumen:}

El objeto de este estudio es el libro Boca Bilingue, publicado en 1966 por Ruy Belo. El libro trae algunas marcas que cruzan toda la obra del autor, como la postura crítica hacia la literatura y la realidad, la temporalidad, la muerte, la memoria. La meta principal será la expresión solitaria del ser que, a veces, se apoderó como un melancólico cuyo acto creativo se dirige hacia la experiencia de la vida cotidiana, a la relación entre la tradición y la novedad. Como se enseña la profesora Ida Alves, en Ruy Belo " la poesía es un compromiso ético con el mundo y una experiencia 
estética fundamental" para la constitución del sujeto poético. A partir del análisis de sus poemas, tenemos la intención de investigar los aspectos diacrónicos y sincrónicos de la obra, con el fin de establecer un paradigma que responde al procedimiento poético de el autor, en cuanto a la noción de experiencia dedicada a la realidad y a la composición poética en su hacer creativo. 